\title{
Evaluation of Golden Proportion in North Indian Individuals with an Aesthetic Smile
}

\author{
Rohit Kulshrestha ${ }^{* 1}$, Kirti Agarwal ${ }^{2}$, Abhay Kant ${ }^{3}$, Kamlesh Singh ${ }^{4}$, Deepak Singh ${ }^{5}$ and Ravi Kant ${ }^{6}$ \\ ${ }^{1}$ Consulting Orthodontist, Private Practice, Mumbai India \\ ${ }^{2}$ Post Graduate Student, Department of Orthodontics and Dentofacial Orthopedics, Chandra Dental College, Luc- \\ know, Uttar Pradesh, India \\ ${ }^{3}$ Post Graduate Student, Department of Prosthodontics, Sri Hasannamba Dental College and Hospital Hassan, Kar- \\ nataka, India \\ ${ }^{4}$ Professor, Department of Orthodontics and Dentofacial Orthopedics, Saraswati Dental College, Lucknow, Uttar \\ Pradesh, India \\ ${ }^{5}$ Professor, Department of Oral and Maxillofacial Surgery, BBD Dental College, Lucknow, Uttar Pradesh, India \\ ${ }^{6}$ Associate Professor, Department of Pedodontics, MRA Medical College, Ambedkar Nagar, India
}

*Corresponding author: Rohit Kulshrestha, Consulting Orthodontist, Private Practice, Mumbai India, Tel: +919870499761, E-mail:kulrohit@gmail.com

Citation: Rohit Kulshrestha, Kirti Agarwal, Abhay Kant, Kamlesh Singh, Deepak Singh, et al. (2017) Evaluation of Golden Proportion in North Indian Individuals with an Aesthetic Smile. J Dent Oral Care Med 3(1): 104. doi: 10.15744/2454-3276.3.104

Received Date: February 14, 2017 Accepted Date: April 19, 2017 Published Date: May 19, 2017

\begin{abstract}
Aim: This study aimed to investigate the existence of the golden proportion between the widths of the maxillary anterior teeth in individuals with an aesthetic smile.

Material and Methods: This study was conducted on 120 subjects ( 60 women and 60 men), with ages ranging from 18 to 25 years. Those subjects whose natural smile did not show any visual tension with regards to the study and their own criteria were selected as having aesthetic smile. An image measurement program was used to measure the apparent mesio-distal widths of six maxillary anterior teeth on the scanned photographs of these subjects. Individual measurements of each maxillary anterior tooth were taken and the golden proportion was compared. The existence of the golden proportion was investigated in the width ratios of maxillary anterior teeth.

Results: For both the genders as well as overall, a significant difference from golden proportion was observed for all the three ratios being evaluated $(\mathrm{p}<0.001)$ (Central Incisor/Lateral Incisor, Lateral Incisor/Canine, Canine/First Premolar).

Conclusion: The golden ratio was not present in all patients who had an aesthetic smile. It is evident from this study that sexual dimorphism exists between the golden proportion in subjects from North India. Individual variation was also seen. This must be kept in mind while planning adjunct procedures along with orthodontic treatment (enameloplasty, inter-proximal reduction) in order to get the best aesthetic results for the patients.
\end{abstract}

Keywords: Golden proportion, Aesthetic smile, Tooth sizes

\section{Introduction}

One of the most important objectives in aesthetic dentistry is the creation of a harmonious smile by changing the proportions of the mesio-distal widths of maxillary anterior teeth when restoring or replacing them. The theory of the "golden proportion" has often been used as a foundation in smile design [1]. The Golden Pro-portion was first described by the Pythagoreans in the sixth century $\mathrm{BC}$, and later by the Euclid the renowned Greek geometrician. This ratio is approximately 1.61803:1; the smaller section is about $62 \%$ of the size of the larger. The rareness of this ratio is that the ratio of the smaller part to the larger part is same as the ratio of larger part to the whole [2]. Ricketts had devised a golden proportion caliper which he used to estab $\neg$ lish and evaluate the ratios between various features of an attractive face [3]. Levin mentioned from his studies that width of the maxillary lateral incisor is in golden proportion to the width of the maxillary central incisor. The same was true for the width of the maxillary canine to the lateral incisor when viewing from the frontal view [4]. Gillen., et al. did a study of 54 subjects and they found out that the golden proportion was rarely seen [5]. This may be due to the fact that their measurements were made di $\neg$ rectly on the casts, rather than on scanned photographs.

In Orthodontics, Ricketts was the first to mention that the physical beauty of the face should be ap $\neg$ proached mathematically [6]. He advocated the use of the golden proportion in that all respects related to facial harmony. Some other authors have also mentioned 
the use of this proportion in anterior aesthetics and have stated the golden proportion is a reliable parameter [7,8]. Some authors have stated that the golden proportion is not present in attractive faces, natural aesthetic smiles and is not suitable to relate to the successive width of the maxillary anterior teeth [9-11]. Due to the contradiction in the above mentioned studies, there is confusion for both the clinician and technician. Therefore, to fill this lacuna the objective of this study was to investigate the existence of the golden proportion between the widths of the maxillary anterior teeth in North Indian individuals having an aesthetic smile.

\section{Material and Methods}

This study was conducted at "Smile Train Centre" Swami Vivekanand Hospital Lucknow India. 120 subjects were taken and were divided into 2 groups Male -60, Female - 60 (mean age 20.43 years). An inclusion criterion for the study was as follows:

a) Age between 18 and 25 years

b) Skeletal and Dental Class I relation with well balanced orthognathic profiles

c) No crowding, spacing or rotation in anterior teeth

d) No history of previous orthodontic treatment or anterior restorations

e) No previous history of trauma to the dentition.

f) Presence of all anterior teeth from premolar to premolar

Those subjects whose natural smile showed any visual tension (crowding, rotations, malformations, fractures, abnormalities etc) with regards to the study and their own criteria were not selected for the study.

A written, informed consent was obtained from all subjects and the Institutional Review Board approval was obtained. A frontal photograph was taken of each individual with an aesthetic smile by D 3200 DSLR camera in natural head position. The patient was told sit in an upright and comfortable position. The upper lip was retracted to clearly display the maxillary anterior teeth as well as its respective gingiva. Lighting and staging were kept constant. All photographs were scanned and saved in a personal computer using an image measurement program (Dimaxis R 2.3.3, Planmeca, and Helsinki, Finland) [12]. This was done to enable measurements of the apparent mesio-distal width of each anterior tooth as seen from the frontal view. All the images were taken in a 1:1 ratio. The zoom function of the program was used to achieve a more precise measurement and indication of the mesial and distal contour of the anterior teeth. Using the software vertical lines were drawn at the mesio-distal contours of all the anterior as seen from the frontal view (Figure 1). The distance between these lines was measured and used to calculate the golden proportion (Table 1,2). All measurements were performed for both the sides by one individual.

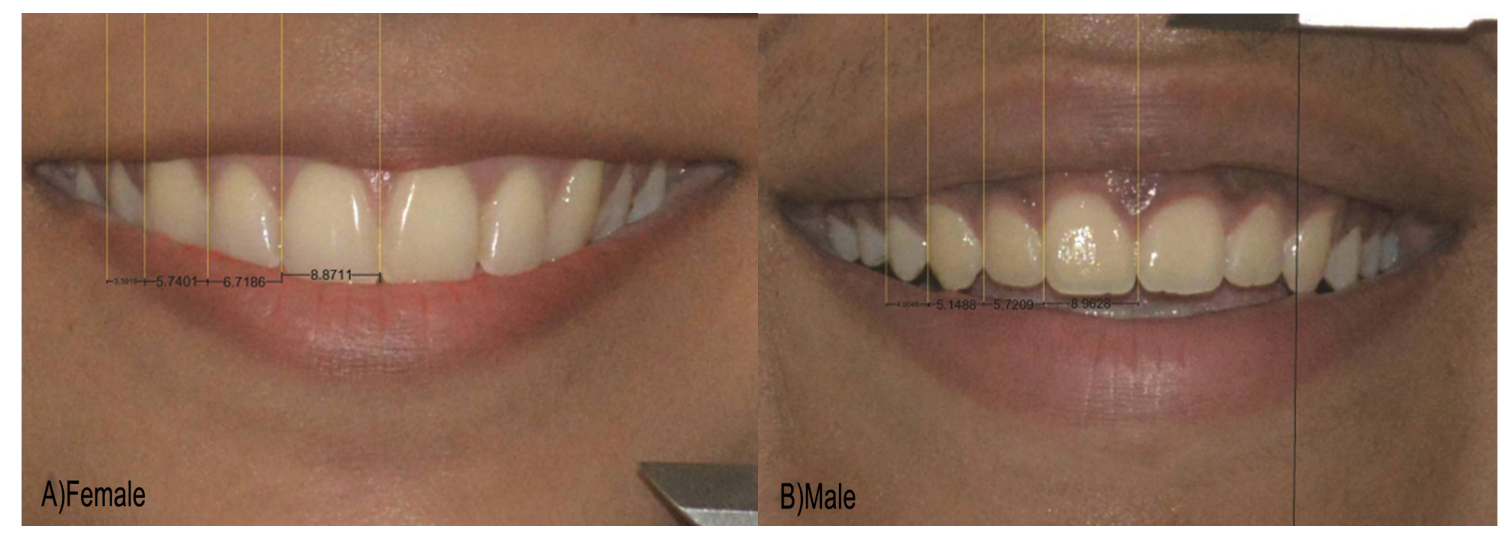

Figure 1: Mesio-distal measurement of all the anterior as seen from the frontal view

\begin{tabular}{|c|c|c|c|c|c|c|}
\hline \multirow{2}{*}{ Parameter } & \multicolumn{2}{|c|}{ Male $(\mathbf{n = 6 0})$} & \multicolumn{2}{c|}{ Female $(\mathbf{n = 6 0})$} & \multicolumn{2}{c|}{ Total $(\mathbf{n = 1 2 0})$} \\
\cline { 2 - 7 } & Mean & SD & Mean & SD & Mean & SD \\
\hline CI & $8.71 \mathrm{~mm}$ & 0.56 & $8.50 \mathrm{~mm}$ & 0.64 & $8.61 \mathrm{~mm}$ & 0.61 \\
\hline LI & $5.93 \mathrm{~mm}$ & 0.66 & $5.91 \mathrm{~mm}$ & 0.62 & $5.92 \mathrm{~mm}$ & 0.64 \\
\hline C & $4.69 \mathrm{~mm}$ & 0.58 & $4.39 \mathrm{~mm}$ & 0.69 & $4.54 \mathrm{~mm}$ & 0.66 \\
\hline P & $3.27 \mathrm{~mm}$ & 0.71 & $3.08 \mathrm{~mm}$ & 0.63 & $3.18 \mathrm{~mm}$ & 0.68 \\
\hline
\end{tabular}

CI - Central Incisor, LI - Lateral Incisor, C - Canine, P - Premolar

Table 1: Measurement of mesio-distal widths of anterior teeth as seen from frontal view

\begin{tabular}{|c|c|c|c|c|c|c|}
\hline \multirow{2}{*}{ Parameter } & \multicolumn{2}{|c|}{ Male $(\mathbf{n = 6 0})$} & \multicolumn{2}{c|}{ Female $(\mathbf{n = 6 0})$} & \multicolumn{2}{c|}{ Total $(\mathbf{n = 1 2 0})$} \\
\cline { 2 - 7 } & Mean & SD & Mean & SD & Mean & SD \\
\hline CI/LI & 1.49 & 0.18 & 1.45 & 0.18 & 1.47 & 0.18 \\
\hline LI/C & 1.28 & 0.21 & 1.37 & 0.23 & 1.33 & 0.22 \\
\hline C/P & 1.52 & 0.55 & 1.49 & 0.46 & 1.51 & 0.50 \\
\hline
\end{tabular}

CI - Central Incisor, LI - Lateral Incisor, C - Canine, P - Premolar

Table 2: Golden Proportion ratio 


\section{Statistical Analysis}

A master file was created with the data, and it was statistically analyzed by using the Statistical Package for Social Sciences Software Version 17 (SPSS Inc. Released 2008. Chicago: SPSS Inc). The data was subjected to descriptive analysis for mean, standard deviation, and $95 \%$ confidence interval. ' $\mathrm{p}$ ' value less than 0.05 was considered to denote a statistically significant association. For comparison of gender groups independent samples't'-test was performed. Ten images were measured again by the 2 other investigators to establish the validity of the taken measurements. A correlation of 0.95 for the three measurements was seen. 10 of the images were measured again under the same conditions 15 days later to establish the reliability of the measurements. A correlation of .97 for the measurements was seen.

\section{Results}

The existence of the golden proportion was found to be nearly similar in the left and right side and for both sexes. It was found that the Golden Proportion ratio was higher in females than in males for lateral incisor/canine (Graph 1). For both the genders as well as collectively, a significant difference $(\mathrm{p}<0.001)$ from golden proportion was observed for all the three ratios being evaluated (Table 3).

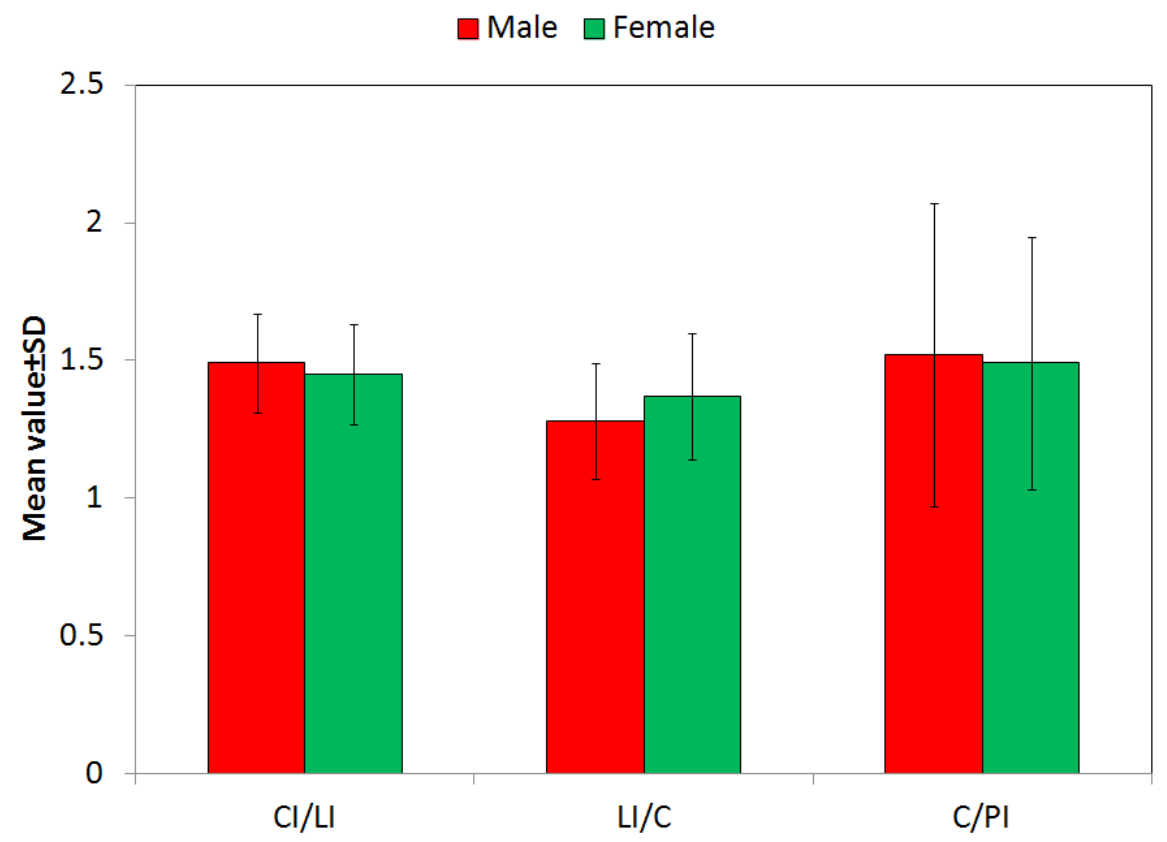

Graph 1: Golden Ratio measurement

\begin{tabular}{|c|c|c|c|c|c|c|}
\hline \multirow{2}{*}{ Parameter } & \multicolumn{2}{|c|}{ Male $(n=60)$} & \multicolumn{2}{|c|}{ Female $(n=60)$} & \multicolumn{2}{|c|}{ Total $(n=120)$} \\
\hline & ' $t$ ' & 'p' & ' $\mathrm{t}$ ' & 'p' & ' $t$ ' & 'p' \\
\hline $\mathrm{CI} / \mathrm{LI}$ & 98.2 & $<0.001$ & 83.3 & $<0.001$ & 125.8 & $<0.001$ \\
\hline $\mathrm{LI} / \mathrm{C}$ & 50.3 & $<0.001$ & 53.8 & $<0.001$ & 73.8 & $<0.001$ \\
\hline $\mathrm{C} / \mathrm{P}$ & 40.9 & $<0.001$ & 30.9 & $<0.001$ & 48.8 & $<0.001$ \\
\hline
\end{tabular}

CI - Central Incisor, LI - Lateral Incisor, C - Canine, P - Premolar Table 3: Significance of difference from Golden Proportion

\section{Discussion}

Determination of a symmetric or geometrical relation among the anterior teeth is important to achieve an aesthetic result. Existence of statistically reliable results will help to support these existing theories. The rule of the golden proportion is as follows: the width of the max $\neg$ illary anterior teeth from the frontal view with the width of the lateral incisor is 0.62 , the width of the canine compared to that of the lateral incisor is 0.62 , while the width of the central incisor compared to that of the lateral is 0.62 [13]. Several studies were conducted to find possible applications of the rule of golden proportion in dentistry [6,14,15]. The golden percentage was a modifica $\neg$ tion which was proposed as a simple and objective tool to assess such dental aesthetic measures such as anterior prominence, symmetry across the midline, and the regressive proportions [16]. The largest study done on the golden proportion involved 376 dental students in Jordan. The authors found that average ratio of the maxillary central incisor, the lateral incisor, and the canine was 1.53:1:0.8. Dimensions that matched the rule of golden proportion were found in only $31.3 \%$ of the women and $27.1 \%$ of the men [17]. 
Rosenstiel., et al. found that golden proportion was seen only when very tall teeth and less desirable teeth were taken into consideration (not for normal height or shorter teeth) [18]. However, the universal use of the golden proportion should no longer be considered since many articles have showed that the golden proportion was not seen in a majority of observed aesthetic smiles. In the current study the existence of the golden proportion was found to be nearly similar in the left and right side and for both sexes. This was also seen in other studies done on golden proportion $[4,7,19]$. It is clear from the above mentioned result that individual variations are not seen in the golden proportion as tooth sizes on both sides are nearly the same unless some malformation or deformity is seen [20,21]. It was found that the Golden Proportion ratio was higher in females than in males for lateral incisor/canine. This sexual dimorphism was also seen in studies done by various other authors $[4,10,20,21]$. This could be seen due to the fact the males have larger teeth sizes than females. Since all the subjects were North Indian we can rule it out. For both the genders as well as collectively, a significant difference from golden proportion was observed for all the three ratios being evaluated. This depends on the individual tooth sizes and the position of the teeth on the arch. Only subjects with aesthetic smiles were taken (without any visual tension) hence the positioning of the teeth in the arch would have been satisfactory. Tooth size plays the major role in this study. Textbooks have suggested that golden proportion is required for an aesthetic smile but results of the current study have shown that golden proportion was not present between the widths of the maxillary anterior teeth in individuals who had an aesthetic smile $[1,3,12,17]$. This may be mainly due to individual variations in each individual. Genetics also plays a major role in tooth sizes. The textbooks studies were done around 30 years ago. Change in environment and lifestyle from childhood also may affect the size of the teeth and development of the facial soft tissues. Further research on this topic is required to obtain clarity on this matter.

\section{Conclusion}

A.The existence of the golden proportion was found to be nearly similar in the left and right side and for both sexes.

B. It was found that the Golden Proportion ratio was higher in females than in males for lateral incisor/canine.

C. Sexual dimorphism in golden proportion was observed for all the anterior teeth being evaluated with males having a higher ratio.

D. Golden proportion is not required for having an aesthetic smile.

\section{References}

1. Levin EI (1978) Dental esthetics and the golden proportion. J Prosthet Dent 40: 244-52.

2. Rosenstiel SF, Land MF, Fujimoto J (2006) Contemporary fixed prosth $\neg$ odontics. Elsevier Health Sciences.

3. Ricketts RM (1982) Divine proportion in facial esthetics. Clin Plast Surg 9: 401-22.

4. Ward DH (2007) A study of dentists' preferred maxillary anterior tooth width proportions: comparing the recurring esthetic dental proportion to other mathematical and naturally occurring proportions. J Esthet Restor Dent 19: 324-39.

5. Gillen RJ, Schwartz RS, Hilton TJ, Evans DB (1994) An analysis of selected normative tooth proportions. Int J Prosthodont. 7: 410-7.

6. Ricketts RM (1982) The biologic significance of the divine proportion and Fibonacci series. Am J Orthod. 81: 351-70.

7. Morley J (1997) Smile design--specific considerations. J Calif Dent Assoc. 25: 633-7.

8. Ahmad I (1998) Geometric considerations in anterior dental aes $\neg$ thetics: restorative principles. Pract Periodontics Aesthet Dent. 10: 813-22.

9. Rossetti A, Menezes MD, Rosati R, Ferrario V, Sforza C (2013) The role of the golden proportion in the evaluation of facial esthetics. Angle Orthod. 83: 801-8.

10. Murty BVS, Ramani N (2008) Evaluation of natural smile: Golden proportion, RED or Golden percentage. J Conserv Dent. 11: 16-21.

11. Agrawal VS, Kapoor S, Bhesania D, Shah C (2016) Comparative photographic evaluation of various geometric and mathematical proportions of maxillary anterior teeth: A clinical study. Indian J Dent Res 27: 32-6.

12. Mahshid M, Khoshvaghti A, Varshosaz M, N Vallaei (2004) Evaluation of "golden proportion" in individuals with an esthetic smile. J Esthet Restor Dent. 16: 185-93.

13. Preston JD (1993) The golden proportion revisited. J Esthet Dent. 5: 247-51.

14. Lombardi RE (1973) The principles of visual perception and their clinical application to denture esthetics. J Prosthet Dent. $29: 358-82$.

15. Magne P, Gallucci GO, Belser UC (2003) Anatomic crown width/length ratios of unworn and worn maxillary teeth in white subjects. J Prosthet Dent. 89: 453-61.

16. Snow SR (1999) Esthetic smile analysis of maxillary anterior tooth width: the golden percentage. J Esthet Dent. 11: 177-84.

17. Ali Fayyad M, Jamani KD, Agrabawi J (2006) Geometric and mathemati $c$ cal proportions and their relations to maxillary anterior teeth. J Contemp Dent Pract. 7: 62-70.

18. Rosenstiel SF, Ward DH, Rashid RG (2000) Dentists' preferences of anterior tooth proportion - A web-based study. J Prosthodont 9: 123-36.

19. Dong J-K, Jin T-H, Cho H-W, Oh S-C (1999) The esthetics of the smile: a review of some recent studies. Int J Prosthodont 12: 9-19.

20. Bukhary SM, Gill DS, Tredwin CJ, Moles DR (2007) The Influence of Varying Maxillary Lateral Incisor dimensions on perceived Smile Aesthetics. Br Dent J. 203: 687-93.

21. Pini NP, de-Marchi LM, Gribel BF, Ubaldini AL, Pascotto RC (2012) Analysis of the golden proportion and width/height ratios of maxillary anterior dentition in patients with lateral incisor agenesis. J Esthet Restor Dent. 24: 402-14. 


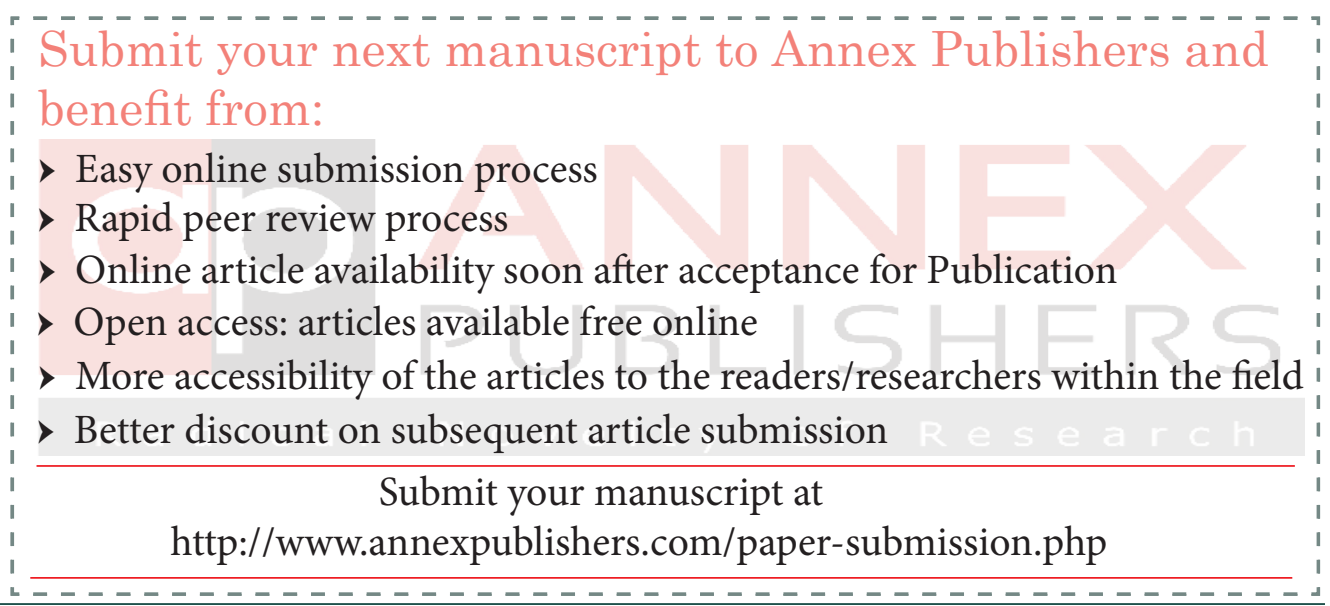

